An e-health interactive self-assessment website (Sanoia $\left.{ }^{\circledR}\right)$ in rheumatoid arthritis. A 12-month randomized controlled trial in 320 patients.

Laure Gossec,1,2 Alain Cantagrel,3, Martin Soubrier,4, Jean-Marie Berthelot,5, Jean-Michel Joubert,6, Bernard Combe,7, Wienia Czarlewski,6, Daniel Wendling,8, Emmanuelle Dernis,9, Laurent Grange,10, Catherine Beauvais,11, Aleth Perdriger,12, Henri Nataf,13, Maxime Dougados,14, Hervé Servy,15

\title{
AUTHOR AFFILIATIONS
}

1 Sorbonne Universités, UPMC Univ Paris 06, GRC-UPMC 08 (EEMOIS), Institut Pierre Louis d'Epidémiologie et de Santé Publique (UMRS 1136), Paris, France

2 Rheumatology Department, Hôpital Pitié Salpêtrière, AP-HP, Paris, France

3 Rheumatology Department, Hôpital de Purpan CHU Toulouse, Toulouse, France; cantagrel.a@chu-toulouse.fr

4 Rheumatology Department CHU Gabriel Montpied, Clermont-Ferrand, France; msoubrier@chu-clermontferrand.fr

5 Rheumatology Department, CHU de Nantes, Nantes, France ; jeanmarie.berthelot@chunantes.fr

6 UCB Pharma, Colombes, France; Jean-Michel.Joubert@ucb.com; Wienia.Czarlewski@ucb.com

7 Rheumatology Department, Hôpital Lapeyronie, Montpellier Université, Montpellier, France ; b-combe@chu-montpellier.fr

8 Rheumatology Department, CHRU Jean Minjoz, Besançon, France; dwendling@chubesancon.fr

9 Rheumatology Department, Centre Hospitalier du Mans, Le Mans, France ; edernis@chlemans.fr

10 Rheumatology Department, CHU Grenoble Alpes-hôpital Sud, Echirolles, France ; LGrange@chu-grenoble.fr

11 Rheumatology Department, Hopital Saint Antoine, APHP, Paris, France ; catherine.beauvais@aphp.fr

12 Rheumatology Department, C.H.R. Hôpital Sud, Rennes, France ; aleth.perdriger@churennes.fr 
13 Private Practice Rheumatology, Mantes La Jolie, France ; irnehfatan@gmail.com

14 Paris Descartes University, Department of Rheumatology - Hôpital Cochin. Assistance Publique - Hôpitaux de Paris ; INSERM (U1153): Clinical epidemiology and biostatistics, PRES Sorbonne Paris-Cité. Paris, France.maxime.dougados@aphp.fr 15 Sanoia, e-Health Services, Gémenos, France; hservy@sanoia.com

\section{INSTITUTION TO WHICH THE WORK SHOULD BE ATTRIBUTED}

Sorbonne Universités, UPMC Univ Paris 06, and Hôpital Pitié-Salpétrière APHP, Paris, France

\section{CORRESPONDING AUTHOR}

Pr. Laure Gossec, Hôpital Pitié-Salpétrière, Service de Rhumatologie, 47-83, boulevard de l'Hôpital - 75013 Paris France

laure.gossec@aphp.fr Tel: +33142178421 Fax: $+33-142177959$

Running title: Sanoia interactive website in RA

Word count: 3233, 3 tables, 2 figures, 38 references; and as online supplement, 1 figure and 3 tables 


\section{ABSTRACT word count 246, limit 250}

Introduction. Sanoia is an online interactive electronic e-health platform developed to allow patient self-assessment and self-monitoring. The objective was to assess in rheumatoid arthritis (RA) patients, the efficacy on patient-physician interactions, of giving access to Sanoia.

Methods. In this French, multi-center, 12-months randomized controlled trial (CarNET: NCT02200068), patients with RA and internet access were randomized to: access without incentives to the Sanoia platform after minimal training, or usual care. The primary outcome was the change from baseline in patient-physician interactions, by the patient-reported Perceived Efficacy in Patient-Physician Interactions (PEPPI-5) questionnaire. The number of accesses to Sanoia was recorded and satisfaction with the platform was assessed through a 0-10 numeric rating scale. Analyses were in Intention to Treat (ITT), on SAS.

Results. Of 320 RA patients (159 Sanoia versus 161 usual care), mean (standard deviation) age was 57.0 (12.7) years, mean (SD) disease duration was 14.6 (11.1) years, 216 (67.5\%) were taking a biologic and $253(79.1 \%)$ were female. Mean (SD) PEPPI scores at baseline and 12 months were 38.6 (8.2) and 39.2 (8.0) (delta=+0.60 [5.52]) versus 39.7 (7.3) and 38.8 (8.0) (delta $=-0.91$ [6.08]) in the Sanoia and control group, respectively $(p=0.01)$. Although mean satisfaction with the platform was very high (1.46 [1.52]), 41 patients (25.7\%) never accessed Sanoia.

Conclusion: Giving RA patients access to the interactive Sanoia e-health platform led to a small improvement in patient-perceived patient-physician interactions. A disjunction between patient satisfaction and access to the platform was noted. E-Health platforms are promising in RA.

Key words: rheumatoid arthritis, disease activity; patient attitude to health; e-health, electronic health records, patient-reported outcome measures, quality of life, quality of health care 


\section{Highlights}

1. In this randomized controlled trial, giving access to the interactive Sanoia e-health platform led to a small improvement in patient-perceived patient-physician interactions.

2. E-Health platforms are promising adjuncts to physician care in RA.

3. Although mean satisfaction with the platform was very high, around a quarter of the patients did not use the interactive platform.

4. Future studies of e-health should measure not only patient satisfaction but a combination of both patient satisfaction and utilization. 


\section{INTRODUCTION}

Interactive online services may be a useful tool for patients with chronic diseases such as rheumatoid arthritis (RA).(1-3) Interactive, online electronic e-Health services which allow patients to self-report patient-reported outcome measures (PROMs) in between visits, and to record events and changes over time, may be helpful in several ways. In particular, such online services may facilitate patient-physician communication. A tight control or treat-totarget management strategy has become the standard of care for RA and there has been growing emphasis on the importance of shared decision-making in RA.(4,5) Patientphysician shared decision-making necessitates open and thorough discussions and good interactions. Thus, in an optic of shared decision-making, online services may be useful in particular if they facilitate patient-physician interactions.

Sanoia is a secure e-health and mobile $(\mathrm{m})$-health platform for patients, which is under the aegis of the French Society of Rheumatology.(6) The platform was developed to allow patient self-assessment, storage of questions to ask to physicians, and self-monitoring of disease status through validated scores and PROMs. $(7,8)$

To our knowledge, most previously published studies on e-health services have mainly focused on patient satisfaction, but have not assessed in a methodologically rigorous way the efficacy of such platforms.(9-13) Given the need for optimal patient-physician interactions, and the specificities of the Sanoia platform, we hypothesized that using Sanoia might render the outpatient visit more efficient and more satisfactory to the patient (and potentially to the physician as well, though this was not assessed here). Another important issue is use of e-health platforms over long periods of time. Although patients may be attracted to such platforms, repeated use over time has been little assessed. $(2,14)$

Thus, the objective of the present trial was to assess the effect of access to the Sanoia ehealth platform on patient-perceived patient-physician interaction efficacy after 12 months. We were also interested in the use of Sanoia and its link with patient-declared satisfaction with the website.

\section{METHODS}

\section{Study design}

CarNET (http://www.clinicaltrials.gov/ct2/show/NCT02200068) was a French 12-month multicenter randomized controlled unblinded trial. Patient inclusions were performed from July 2014 to February 2015 and patient follow-up was finished in March 2016. Follow up was 
undertaken in 13 rheumatology centers across France: most were tertiary care centers and one was a rheumatology private practice. All patients received at inclusion full information; no signed consent was necessary according to the ethical committee. Ethical approval was obtained from the institutional review board (CPP Ile de France III) and the human research ethics committee (CCTIRS, number 13.569).

\section{Patients}

Patients were enrolled by their treating rheumatologist. The patients had confirmed RA (according to the ACR/EULAR classification criteria (15) and to the rheumatologist's opinion), they were followed-up by the same rheumatologist for more than one year and they had internet access.

\section{Intervention}

Patients were allocated to 2 groups: a) possibility of access to the Sanoia platform, or b) usual care (continuation of normal internet use without Sanoia access). In the Sanoia arm, patients received a 30-minute information/training call to help them set up their Sanoia accounts. After this initial call, patients were not prompted to use the platform either in the eCRF or by their physicians at any point. If they recorded information in Sanoia, they could share this with their physician during visits, at their own instigation.

Sanoia is an e-health platform developed to allow self-assessment of health and disease status.(6) Sanoia (http://www.sanoia.com) was launched in 2010, and provides online secure health records that allow patients to track and store their own health data (Supplementary online Figure 1). Patients can enter data on perceived health (in particular, through the RAPID3, Health Assessment Questionnaire and RA Impact of Disease scores, as well as symptoms as free text), blood test results and other features and follow their evolution graphically. They can also store questions to ask their physicians. It is easy in Sanoia to generate summary reports which can then be downloaded or printed in view of data-sharing. Sanoia is available in 14 languages on PCs, tablet computers and smartphones.(6)

Follow up was performed using a home-based e-CRF completed at months 3,6 , and 12 by the patient, without physician intervention and unrelated to ongoing medical follow-up visits.

The rest of the follow-up and therapeutic decisions were performed according to usual care.

\section{Primary outcome}

The primary outcome was change in patient-physician interactions, assessed using the Perceived Efficacy in Patient-Physician Interactions questionnaire (PEPPI-5), over 12 
months. The PEPPI-5 consists of 5 items, each starting with "How confident are you in your ability to..." (eg. "...know what questions to ask a doctor?") (Table 1 and Supplementary online Table 1).(16, 17) Patients rate each item on an 11-point scale; $0=$ not at all confident, $10=$ very confident. Total PEPPI-5 scores range 0-50; higher scores represent higher perceived self-efficacy in patient-physician interactions. The questionnaire was translated and adapted to French, after obtaining authorization from its authors, following validated procedures.(18)

\section{Use of Sanoia}

For patients randomized to the active group (i.e., with access to Sanoia), use of the Sanoia platform was automatically collected through platform logs. Of note, the investigators did not prompt their patients to enter data in the platform, as we assessed here the active role of the patient.

At the end of the study the patients used the home-based e-CRF to record satisfaction with the platform (0-10 numeric rating scale; $0=$ completely satisfied, $10=$ not at all satisfied), and barriers to Sanoia use, from a pre-specified list which included poorly organized site, technical issues, fear of internet in general, not useful because of remission, other reason, no barriers.

\section{Other data collected}

Characteristics of RA patients were collected at baseline and included gender, age, disease duration and ongoing pharmacological arthritis treatment including conventional synthetic and biological disease-modifying drugs. Patients self-reported their socio-professional category, work status, and if they had already undergone patient education and were or not, members of a patients association.

Where available, the status for rheumatoid factor (RF) and for anti-cyclic citrullinated peptide (anti-CCP), and the presence of radiographic erosions were recorded, as recorded in the medical files, based on local readings in the context of usual care. At baseline, disease activity was assessed by the last available Disease Activity Score 28 (DAS28) in RA patients, and disability was self-assessed using the Health Assessment Questionnaire Disability Index (HAQ-DI, range 0-3).(19,20)

Secondary outcomes included the RA Impact of Disease (RAID) questionnaire, which includes 7 questions on disease impact, and its subscale on coping.(21) Furthermore, a numeric rating scale (NRS) question was developed by the steering committee with the help of a patient education nurse specialist, to assess patient-perceived quality of care. The 
question used was: "Considering all the resources available (interactions with your physician, your pharmacist, the care team including nurse and physiotherapist), and also other information and support resources like patients associations, brochures, internet, how do you consider the quality of care of your rheumatoid arthritis?" scored 0 : very bad ; to 10 : excellent."

\section{Statistical analyses}

Sample size: based on expected baseline scores of 37 (standard deviation 12) (17), and on no change in the control group and an improvement of 4 points in the Sanoia group, considering a statistical power of $85 \%$ and a significance level of $5 \%, 132$ participants had to be analysable in each group. To account for $20 \%$ of patients who could not be analysed, we aimed to include 160 patients per group.

Patient characteristics were analysed descriptively. Comparisons between groups were nonparametric, in Intention to Treat (ITT) and missing data were imputed using Last Observation Carried Forward (using the 6 month or 3 month data if necessary).

Use of the platform was analysed descriptively over time. Baseline patient characteristics associated with more frequent use (above the median) vs not, were compared by univariate and multivariate stepwise logistic regression. Factors analysed included patient demographics, disease characteristics, activity and treatment, and RAID/coping questions. All analyses were performed on SAS the Statistical Analysis System version 9.3.2.

\section{RESULTS}

\section{Patient description}

In all, 320 patients were assigned randomly to 2 groups, either with access to the Sanoia platform ( $n=159)$, or with normal internet use without Sanoia access $(n=161)$.

Baseline demographics were well balanced between both groups (Table 2). Of $320 \mathrm{RA}$ patients (159 vs 161, Sanoia vs usual care), mean (SD) age was 57.0 (12.7) years, mean 
(SD) disease duration was 14.6 (11.1) years, and 253 (79.1\%) were female. Mean DAS28 was 2.65 (1.20), 54.1\% were in DAS28 remission (<2.6); $216(67.5 \%)$ were taking a biologic.

Twelve-month data were available for 244 (76.0\%) patients.

\section{Primary outcome: changes in PEPPI}

At baseline, the mean PEPPI-5 score was 39.2 (standard deviation, SD: 7.8) and the median was 40. Overall, a small improvement in PEPPI-5 score was seen in patients with access to the Sanoia platform compared to patients in the control group, for whom a concurrent decline in PEPPI-5 scores was observed, leading to a significant difference (Figure 1 and Table 3): mean (SD) changes in PEPPI from baseline to 12 months were 38.6 (8.2) to 39.2 (8.0) (delta $=+0.60$ [5.52]) vs $39.7(7.3)$ to $38.8(8.0)$ (delta=-0.91 [6.08]) in Sanoia vs control group $(p=0.01)$.

Of note, post-hoc analyses indicated greater efficacy at 6 months: delta=-1.43 (6.65) vs +0.52 (5.42), in the control group vs Sanoia group respectively, $p=0.002$.

Changes were similar across the 5 PEPPI-5 questions (Supplementary online Table 2).

\section{Use of Sanoia}

Patients in the Sanoia group were asked to assess satisfaction between 0 and 10 (where total satisfaction was scored 0) with the platform after 12 months: satisfaction was high among the 110 patients still followed-up: mean, 1.5 (SD 1.5), median 1.

In the Sanoia group, 118/159 (74\%) patients accessed the platform at least once, whereas $41(26 \%)$ patients never accessed the Sanoia platform at any time. Over the 12 months of the study, $81(51 \%)$ patients accessed the platform at least twice, with a median of 2 and a mean of 4.4 (SD: 11.3) connections per patient over the 12-month period. However, use of the platform decreased over time, in particular over the first months (Figure 2).

The main limitation expressed by patients (12\%) was that the platform was not useful because they were in disease remission (Supplementary online Table 3)

In multivariate analyses, the only factor found to be related to connecting more than twice to the platform was being a member of a patient association (odds ratio, 1.44 (95\% confidence interval, 1.17-1.77, $\mathrm{p}=0.0007$ ). In the group with high versus low number of connections, the percentage of patient association members was $24.7 \%$ versus $6.5 \%$, respectively.

\section{Other outcomes}


Changes in perceived quality of care were different between the groups (Table 3): mean (SD) changes in quality of care NRS from baseline to 12 months were 8.2 (1.7) to 8.3 (1.6) (delta $=+0.06$ [1.44]) vs $8.2(1.6)$ to $7.8(1.9)$ (delta=-0.42 [1.63]) in the Sanoia vs control group $(\mathrm{p}=0.02)$.

RAID changes did not differ between groups; both the Sanoia and the control group saw a numerical improvement in RAID score at 12 months; a further numerical improvement was seen in the coping component of the RAID for the Sanoia group although differences were not statistically significant (Table 3).

\section{DISCUSSION}

We demonstrated that giving patients access to the interactive Sanoia e-health platform led to a statistically significant, albeit small, improvement in patients' perception of patientphysician communication quality and quality of care, confirming the potential usefulness of an e-health intervention when used in conjunction with physician care in RA. The results also suggest that patient satisfaction should be interpreted with caution, since despite high levels of satisfaction reported with the platform, only half of patients used the platform more than twice in 12 months, suggesting that future research should consider a combination of both patient satisfaction and utilization.

This study has strengths and weaknesses. This trial was one of the first to measure the impact of an e-health tool on the quality of the patient's efficacy in patient-physician interactions, as opposed to simply measuring patient satisfaction with the tool. Patientphysician interactions are an important aspect of care and may be a key aspect of shared decision-making. $(4,5,22)$ However, as with many aspects of holistic care, patient-physician interactions pose difficult assessment challenges. In the present study, we chose to use the PEPPI which appeared to us as the best questionnaire available for our purposes. Although the PEPPI is a validated questionnaire, it has not been previously used in RA; furthermore, responsiveness has not been assessed. The PEPPI might not have been the best outcome since some of the questions relate more to the physician attitude than to patient empowerment, which is the key notion which Sanoia could improve. This is confirmed by the small but statistically significant improvement in patient-reported quality of care, found in the present study. Of note also, differences observed were small and probably below minimal 
clinically important differences (though such thresholds are not available for the PEPPI).The patient's status was not assessed by a physician as part of this study, over time. It is possible that changes to patients' disease activity and treatment patterns may have occurred and this may have modified perceived interactions between patients and physicians.

It is interesting to note in the present study, that the statistically significant difference in the change in patient-physician interactions (PEPPI scores) over the study duration was due to a slight improvement in the Sanoia group but also a slight worsening in the control group. The improvement in the intervention group may have been limited by the surprisingly high baseline PEPPI values, reflecting excellent interactions before the study. Indeed, the results were better than previously reported in breast cancer.(17) The worsening in the control group may indicate dissatisfaction of patients who were assigned to the control group, especially given this was an unblinded study. Indeed, the choice of a randomized controlled trial, although leading to higher quality data, is often difficult for non-pharmacological interventions (23). The only previous randomized trial of e-health in rheumatology performed by Alam et al indicated the complex web-based intervention had a positive impact on both self-care and empowerment; however effect sizes were small.(13) Patient follow-up was correct and all analyses were performed as ITT thus the results are robust.

Online services may help for patient self-monitoring.(2) In outpatient clinics that monitor patients using outcome measures as standard practice, $\sim 75 \%$ of patients with RA have been reported to be in remission or in low disease activity.(24) PROMs have been described as 'critical, relevant and complementary' in the context of the physician-patient interaction.(25) In an optic of "measuring is getting better" (also called Quantify Self), better knowledge of one's state may improve that state. $(26,27)$ Remote monitoring and reporting of PROMs may facilitate a treat-to-target approach both through these aspects and potentially through patient empowerment. This could potentially lead to benefits both in patient adherence and in disease activity control.(26,28-30)

In the present study, patient inclusion was rapid and easy, indicating people with RA at least in France, may have an initial positive outlook on e-health interventions. Indeed this is a topical subject given the interest in e-health. $(31,32)$ However, in the present study patients did not all feed information longitudinally to the Sanoia website. Perhaps patients lose interest in websites - as may be suggested by the number of new websites created each year in particular in e-health. $(32,33)$ A recent study in the US found similar results: of 1946 RA patients who agreed to voluntarily complete PROs in a mobile application, $20.6 \%$ never contributed any PRO information, 53.3\% answered once, and only $26.1 \%$ answered at least twice.(14) Surprisingly, the present study evidenced a disjunction between patient 
satisfaction with the website, and actual (repeated) use of the website. This is interesting in several ways. Firstly, it puts into question many of the previous publications on websites in ehealth since most of these previous studies have use satisfaction scores as the only marker of quality of the website. $(9-12,34)$ We feel this indicates future research into e-health should consider a combination of both patient satisfaction and utilization. Secondly, these findings raise questions around why patients would not want to use an interactive platform. It is noteworthy that in the present study, the patients had all consented to participate in this ehealth based randomized controlled trial so would be supposed to be inclined in favor of ehealth. However, this study differed from other e-health tool studies in that patients were not prompted to use the platform by their physicians at any point after initial training - the decision to use the platform was determined entirely by the patient with no further reinforcement. Our hypothesis was that patients would feel empowered and decide themselves to show the data to the physician during visits. However, the data-sharing was not measured and cannot be confirmed. Future research should propose a process, to facilitate physician access to patient data at each consultation, to motivate patients.

There are many other possible reasons for loss of interest in the website. The website content was developed with input from health care providers and patient associations and the website is user-friendly, thus we do not believe the practicality of the website is in question. Maybe the multiplicity of screens and complexity of some of the items should be discussed. However, the scores which could be of use in practice in RA, were chosen through an expert-driven approach within a French Society of Rheumatology working group. Perhaps patients simply lose interest with self-assessment over time.There has been a concern that use of IT applications by patients with RA may be limited by their age and manual disability.(34) However, a recent study found that manual disability in patients with $\mathrm{RA}$ is not an obstacle for using mobile applications. The present study indicated that practical issues were rarely cited as a barrier.(35) Another worry with e-health is confidentiality of data (36) but here again, this was rarely raised by the patients in our study. Of note, cybersecurity is an issue which is central to Sanoia and patients may have been reassured by this. The only barrier which was regularly cited was related to the good status. Indeed, it is highly possible that when the disease is in remission, patients may want to "forget" their disease. Then, e-health platforms would be most useful during periods when the disease is less wellcontrolled. $(37,38)$ A recent review on e-health suggested some patients might be better candidates for e-health remote self-monitoring of disease status: i.e., patients with a high technological understanding, those with high engagement with their own disease management, those with barriers to frequent clinic visits, and those at high risk of flare.(2). In the present study, patients who connected most frequently to the platform were found to be 
more often members of a patient association. Of note, no campaigns to promote Sanoia were ongoing through patient organisations at the time of the study. Thus, our interpretation of the link between use of Sanoia and patient associations is high personal engagement in disease management. This confirms partly the hypotheses of our colleagues.(2)

In conclusion, this study has brought to light several important findings. By showing in a randomized controlled trial setting that access to Sanoia improved slightly but significantly patient-physician interactions, this study indicates that e-health platforms are promising adjuncts to physician care in RA. On the other hand, given the disjunction between patientreported satisfaction with the platform and its actual use, we feel future studies of e-health should consider a combination of both patient satisfaction and utilization. Further research could also explore the impact of the platform on physician-perceived quality of patientphysician interactions. 


\section{ACKNOWLEDGMENTS}

The CarNET randomized controlled trial was funded by UCB Pharma and Sanoia. We thank the patients and their caregivers as well as the investigators and their teams who contributed to this study, in particular Alain Saraux (Brest). We thank Christian l'Amour (Paris), patient education nurse, and Cécile Fumeron, patient research partner, as well as the patient association: Association nationale de défense des patients atteints de polyarthrite rhumatoïde (ANDAR) for help in developing the patient questions. We thank Adrien Etcheto, Cochin Hospital Paris for the statistical analyses.

Funding: the CarNET randomized controlled trial was funded by UCB France and e-Health Services Sanoïa. The study was designed, performed and analysed by the coauthors. Some coauthors are employees by UCB France and e-Health Services Sanoia: they participated fully in the conception, realization and interpretation of the study. Apart from that, UCB France gave a grant for this study to e-Health Services Sanoia which played the role of CRO (except analyses). Employees of e-Health Services Sanoia performed the regulatory processing officering, the centers opening, the study initiation calls with the patients and the electronic data collection. UCB received reports of inclusions progress on a monthly basis. Neither UCB nor e-Health Services interfered in the analysis which followed a pre-defined analysis plan and was done in Cochin hospital.

\section{DISCLOSURES OF INTEREST}

JM Joubert and W Czarlewski are employees of UCB France. H Servy is the principal shareholder of the e-Health Services Sanoïa platform editor company. Sanoïa received unrestricted grants from UCB, Nordic and MSD over the 2 years of the study. The other authors or their institutions have received honoraria for this study from e-Health Services ( $<10,000$ euros). No other relevant disclosures for this paper.

\section{REFERENCES}

1. Gossec L, Dougados M, Dixon W. Patient-reported outcomes as end points in clinical trials in rheumatoid arthritis. RMD Open. 2015;1(1):e000019.

2. van Riel $\mathrm{P}$, Alten $\mathrm{R}$, Combe $\mathrm{B}$, Abdulganieva $\mathrm{D}$, Bousquet $\mathrm{P}$, Courtenay $\mathrm{M}$, et al. Improving inflammatory arthritis management through tighter monitoring of patients and the use of innovative electronic tools. RMD Open. 2016;2(2):e000302.

3. DasMahapatra P, Raja P, Gilbert J, Wicks P. Clinical trials from the patient perspective: survey in an online patient community. BMC Health Serv Res. 2017;17(1):166. 
4. Smolen JS, Breedveld FC, Burmester GR, et al. Treating rheumatoid arthritis to target: 2014 update of the recommendations of an international task force. Ann Rheum Dis 2016;75:3-15.

5. Smolen JS, Landewé R, Bijlsma J, Burmester G, Chatzidionysiou K, Dougados M, et al. EULAR recommendations for the management of rheumatoid arthritis with synthetic and biological disease-modifying antirheumatic drugs: 2016 update. Ann Rheum Dis. 2017;76(6):960-977.

6.Sanoia, Fiche santé, Retrieved June 2017 from https://www.sanoia.com/pr.

7. Chiche L, Brescianini A, Mancini J, Servy H, Durand JM. Evaluation of a prototype electronic personal health record for patients with idiopathic thrombocytopenic purpura. Patient Prefer Adherence. 2012;6:725-34.

8. Trijau S, Servy H, Selamnia A M, Pradel V, Lafforgue P, Pham T. Personal Health Records in Rheumatoid Arthritis: Quality and Adhesion Factors. [abstract]. Arthritis Rheum 2011;63 Suppl $10: 149$.

9. Shigaki CL, Smarr KL, Siva C, Ge B, Musser D, Johnson R. RAHelp: an online intervention for individuals with rheumatoid arthritis. Arthritis Care Res (Hoboken). 2013;65(10):1573-81.

10. Zuidema RM, van Gaal BG, van Dulmen S, Repping-Wuts H, Schoonhoven L. An Online Tailored Self-Management Program for Patients With Rheumatoid Arthritis: A Developmental Study. JMIR Res Protoc. 2015 25;4(4):e140.

11. Smarr KL, Musser DR, Shigaki CL, Johnson R, Hanson KD, Siva C. Online selfmanagement in rheumatoid arthritis: a patient-centered model application. Telemed $\mathrm{J} E$ Health. 2011;17(2):104-10.

12. Kostova Z, Caiata-Zufferey M, Schulz PJ. Can social support work virtually? Evaluation of rheumatoid arthritis patients' experiences with an interactive online tool. Pain Res Manag. 2015;20(4):199-209.

13. Allam A, Kostova Z, Nakamoto K, Schulz PJ. The effect of social support features and gamification on a Web-based intervention for rheumatoid arthritis patients: randomized controlled trial. J Med Internet Res. 2015 Jan 9;17(1):e14.

14. Nowell WB, Yun H, Willig J, Beaumont J, Johnson B, Ginsberg S et al. What factors relate to patients contributing longitudinal data using smartphone technology? Findings from RA patients participating in ArthritisPower Registry. Ann Rheum Dis 2017: 76 (suppl 2): 448 (abstract THU0643).

15. .Aletaha D, Neogi T, Silman AJ, Funovits J, Felson DT, Bingham CO 3rd, et al. 2010 rheumatoid arthritis classification criteria: an American College of Rheumatology/European League Against Rheumatism collaborative initiative. Ann Rheum Dis. 2010;69(9):1580-8.

16. ten Klooster PM, Oostveen JC, Zandbelt LC, Taal E, Drossaert CH, Harmsen EJ, et al. Further validation of the 5 -item Perceived Efficacy in Patient-Physician Interactions (PEPPI5) scale in patients with osteoarthritis. Patient Educ Couns . 2012; 87(1) :125-130.

17. Maly RC, Frank JC, Marshall GN, DiMatteo MR, Reuben DB. Perceived efficacy in patient-physician interactions (PEPPI): validation of an instrument in older persons. J Am Geriatr Soc. 1998;46(7):88994.

18. Epstein J, Santo RM, Guillemin F. A review of guidelines for cross-cultural adaptation of questionnaires could not bring out a consensus. J Clin Epidemiol. 2015;68(4):435-41. 
19. Prevoo ML, van 't Hof MA, Kuper HH, van Leeuwen MA, van de Putte LB, van Riel PL. Modified disease activity scores that include twenty-eight-joint counts. Development and validation in a prospective longitudinal study of patients with rheumatoid arthritis. Arthritis Rheum 1995;38(1):44-48. PMID: 7818570

20. Guillemin F, Brainçon S, Pourel J. [Measurement of the functional capacity in rheumatoid polyarthritis: a French adaptation of the Health Assessment Questionnaire (HAQ)]. Rev Rhum Mal Osteoartic. 1991;58(6):459-65.

21. Gossec L, Paternotte S, Aanerud GJ, Balanescu A, Boumpas DT, Carmona L, et al. Finalisation and validation of the rheumatoid arthritis impact of disease score, a patientderived composite measure of impact of rheumatoid arthritis: a EULAR initiative. Ann Rheum Dis. 2011;70(6):935-42.

22. Shay LA, Lafata JE. Understanding patient perceptions of shared decision making. Patient Educ Couns. 2014;96(3):295-301.

23. Boutron I, Tubach F, Giraudeau B, Ravaud P. Methodological differences in clinical trials evaluating nonpharmacological and pharmacological treatments of hip and knee osteoarthritis. JAMA. 2003;290(8):1062-70.

24. Haugeberg G, Hansen IJ, Soldal DM, Sokka T. Ten years of change in clinical disease status and treatment in rheumatoid arthritis: results based on standardized monitoring of patients in an ordinary outpatient clinic in southern Norway. Arthritis Res Ther 2015;17:219.

25. Peláez-Ballestas I. Patient reported outcome measures: what is their importance? Reumatol Clin 2012;8:105-6.

26. Sargious A, Lee SJ. Remote collection of questionnaires. Clin Exp Rheumatol 2014;32(Suppl 85):S168-72.

27. Appelboom G, LoPresti M, Reginster JY, Sander Connolly E, Dumont EP. The quantified patient: a patient participatory culture. Current Medical Research and Opinion 2014: 30:12, 2585-7.

28. Alemao E, Joo S, Kawabata H, Al MJ, Allison PD, Rutten-van Mölken MP, et al. Effects of Achieving Target Measures in Rheumatoid Arthritis on Functional Status, Quality of Life, and Resource Utilization: Analysis of Clinical Practice Data. Arthritis Care Res (Hoboken).2016;68(3):308-17.

29. McManus RJ, Mant J, Haque MS, Bray EP, Bryan S, Greenfield SM, et al. Effect of selfmonitoring and medication self-titration on systolic blood pressure in hypertensive patients at high risk of cardiovascular disease: the TASMIN-SR randomized clinical trial. JAMA. 2014 Aug 27;312(8):799-808.

30. Aikens JE, Rosland AM, Piette JD. Improvements in illness self-management and psychological distress associated with telemonitoring support for adults with diabetes. Prim Care Diabetes. 2015;9(2):127-34.

31. McConnell MV, Shcherbina A, Pavlovic A, Homburger JR, Goldfeder RL, Waggot D, et al. Feasibility of Obtaining Measures of Lifestyle From a Smartphone AppThe MyHeart Counts Cardiovascular Health Study. JAMA Cardiol. 2017;2(1):67-76.

32. Khoury MJ, loannidis JP.Medicine. Big data meets public health. Science. 2014 Nov 28;346(6213):1054-5. doi: 10.1126/science.aaa2709. 
33. Ehrenstein V, Nielsen H, Pedersen AB, Johnsen SP, Pedersen L. Clinical epidemiology in the era of big data: new opportunities, familiar challenges. Clin Epidemiol. $2017 \mathrm{Apr}$ 27;9:245-250.34. Wicks P, Stamford J, Grootenhuis MA, Haverman L, Ahmed S. Innovations in e-health. Qual Life Res. 2014;23(1):195-203.

35. Sikorska-Siudek K, Przygodzka M, Bojanowski S, et al. Mobile application for patients with rheumatoid arthritis (RA) as a supporting tool for disease activity monitoring: its usability and interoperability. Ann Rheum Dis 2015;74(Suppl 2):986. [abstract AB0280].

36. Wilkowska W, Ziefle M. Privacy and data security in E-health: Requirements from the user's perspective Health Informatics J. 2012;18(3):191-201.

37. Bykerk VP, Lie E, Bartlett SJ, Alten R, Boonen A, Christensen R, et al. Establishing a core domain set to measure rheumatoid arthritis flares: report of the OMERACT 11 RA flare Workshop. J Rheumatol. 2014;41(4):799-809.

38. Pincus T. Electronic eRAPID3 (Routine Assessment of Patient Index Data): opportunities and complexities. Clin Exp Rheumatol. 2016;34(5 Suppl 101):S49-S53. 
Table 1. The PEPPI-5 questionnaire $(16,17)$

How confident are you in your ability to:

1) Know what questions to ask your doctor?

$(0=$ Not confident, $10=$ Completely confident $)$

\begin{tabular}{lllllllllll}
0 & 1 & 2 & 3 & 4 & 5 & 6 & 7 & 8 & 9 & 10 \\
\hline
\end{tabular}

2) Get an answer to your questions from the doctor?

$(0=$ Not at all confident, $10=$ Extremely confident $)$

\begin{tabular}{lllllllllll}
0 & 1 & 2 & 3 & 4 & 5 & 6 & 7 & 8 & 9 & 10 \\
\hline
\end{tabular}

3) To make the most out of consultations with your doctor?

$(0=$ Not at all confident, $10=$ Extremely confident $)$

\begin{tabular}{lllllllllll}
0 & 1 & 2 & 3 & 4 & 5 & 6 & 7 & 8 & 9 & 10 \\
\hline
\end{tabular}

4) To ensure the doctor takes your primary health concerns seriously?

$(0=$ Not at all confident, $10=$ Extremely confident $)$

\begin{tabular}{lllllllllll}
0 & 1 & 2 & 3 & 4 & 5 & 6 & 7 & 8 & 9 & 10 \\
\hline
\end{tabular}

5) To get your doctor to take action regarding you main health concerns?

$(0=$ Not at all confident, $10=$ Extremely confident $)$

\begin{tabular}{lllllllllll}
0 & 1 & 2 & 3 & 4 & 5 & 6 & 7 & 8 & 9 & 10 \\
\hline
\end{tabular}


Table 2. Baseline patient characteristics

\begin{tabular}{|c|c|c|c|}
\hline & $\begin{array}{l}\text { Whole population } \\
\quad(\mathrm{N}=320)\end{array}$ & $\begin{array}{l}\text { Sanoia group } \\
N=159\end{array}$ & $\begin{array}{l}\text { Control } \\
\text { group } \\
\mathrm{N}=161\end{array}$ \\
\hline Age, years, mean (SD) & $57.0(12.7)$ & $56.1(13.1)$ & $58.0(12.2)$ \\
\hline Female, n (\%) & $253(79.0)$ & $132(83.0)$ & $121(75.2)$ \\
\hline Duration of disease, years, mean (SD) & $14.6(11.1)$ & $15.0(11.5)$ & $14.8(10.7)$ \\
\hline Erosive disease, n (\%) & $218(68.1)$ & $109(68.6)$ & $109(67.8)$ \\
\hline $\begin{array}{l}\text { Positivity for rheumatoid factor or } \\
\text { ACPA, } n(\%)\end{array}$ & $255(79.7)$ & $125(78.6)$ & $130(70.8)$ \\
\hline University-level studies, n (\%) & $166(51.9)$ & $85(53.5)$ & $81(50,3)$ \\
\hline Currently in paid employement, $\mathrm{n}(\%)$ & $176(55.0)$ & $90(56.6)$ & $86(53.1)$ \\
\hline $\begin{array}{l}\text { Previous patient education programme, } \\
\mathrm{n}(\%)\end{array}$ & $70(21.9)$ & $37(23.3)$ & $33(20.1)$ \\
\hline Member of a patient association, $\mathrm{n}(\%)$ & $49(15.3)$ & $25(15.7)$ & $24(14.9)$ \\
\hline DAS28, mean (SD) & $2.65(1.2)$ & $2.7(1.2)$ & $2.6(1.2)$ \\
\hline HAQ-DI (0-3) mean (SD) & $0.8(0.7)$ & $0.8(0.7)$ & $0.8(0.7)$ \\
\hline Treatment with methotrexate, n (\%) & $232(72.5)$ & $123(77.3)$ & $109(67.7)$ \\
\hline Treatment with biologics, n (\%) & $216(67.5)$ & $115(72.3)$ & $101(62.7)$ \\
\hline $\begin{array}{l}\text { Treatment with oral glucocorticoids, } n \\
(\%)\end{array}$ & $109(95.6)$ & $57(96.6)$ & $52(94.5)$ \\
\hline
\end{tabular}

DAS28: Disease Activity Score on 28 joints; HAQ-DI: Health Assessment Questionnaire Disability Index, DMARD: disease-modifying anti-rheumatic drug. 
Figure 1. Change in PEPPI over 12 months

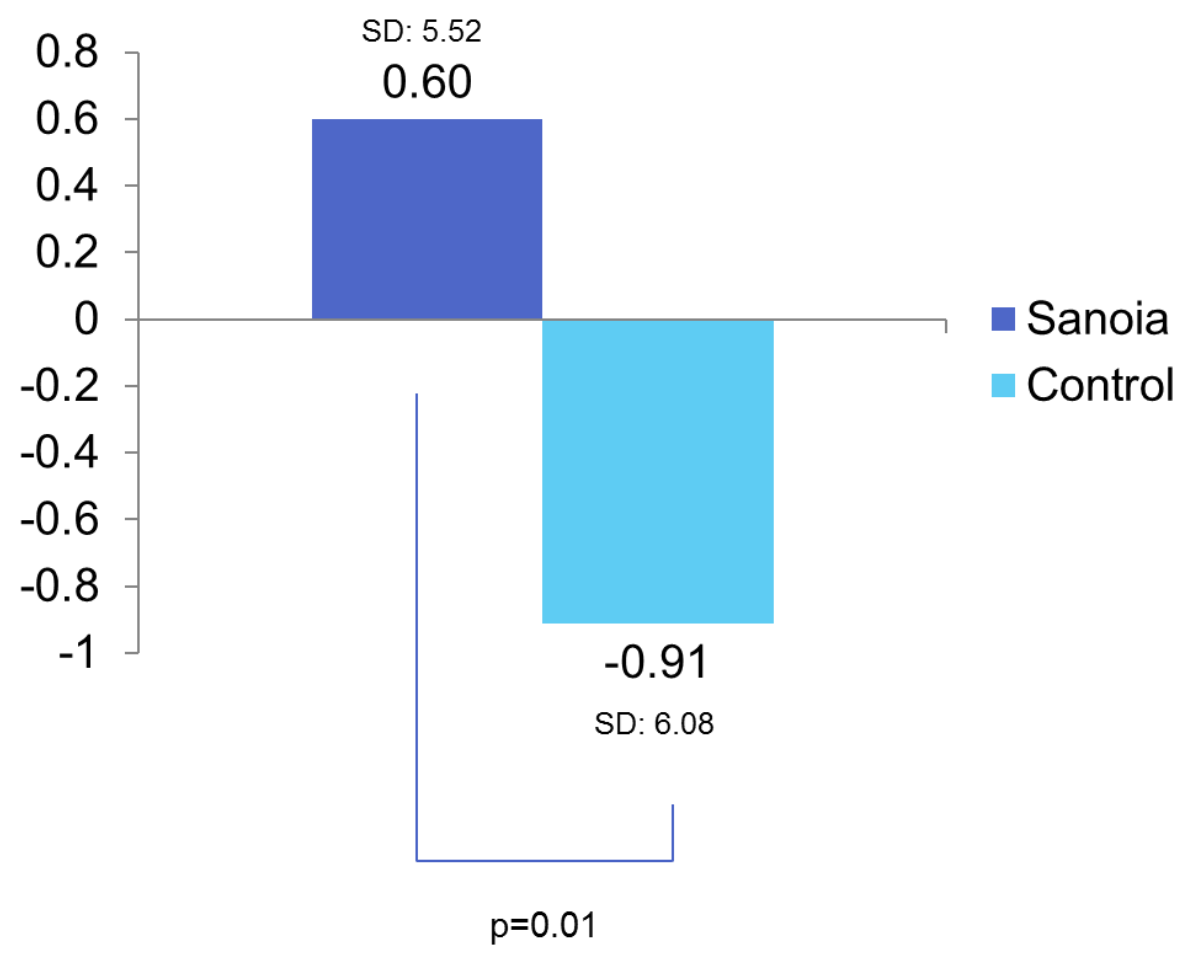


Table 3. Outcomes at baseline and at 12 months and change in outcomes in the Sanoia and control groups

\begin{tabular}{|c|c|c|c|c|c|c|c|}
\hline Outcome & $\begin{array}{c}\text { Sanoia } \\
\text { group : } \\
\text { baseline } \\
N=159\end{array}$ & $\begin{array}{c}\begin{array}{c}\text { Sanoia } \\
\text { group }\end{array} \\
\text { completers: } \\
12 \text { months } \\
\mathrm{N}=110\end{array}$ & $\begin{array}{c}\text { Sanoia } \\
\text { group : } \\
\text { change } \\
\text { from } \\
\text { baseline to } \\
12 \text { months } \\
\text { (ITT } \\
\text { analysis) } \\
\mathrm{N}=159\end{array}$ & $\begin{array}{c}\begin{array}{c}\text { Control } \\
\text { group: } \\
\text { baseline } \\
\mathrm{N}=161\end{array} \\
\end{array}$ & $\begin{array}{c}\text { Control } \\
\text { group } \\
\text { completers: } \\
12 \text { months } \\
\mathrm{N}=134\end{array}$ & $\begin{array}{c}\text { Control } \\
\text { group : } \\
\text { change } \\
\text { from } \\
\text { baseline to } \\
12 \text { months } \\
\text { (ITT } \\
\text { analysis) } \\
\mathrm{N}=161\end{array}$ & $\begin{array}{c}\text { p value } \\
\text { comparing } \\
\text { changes } \\
\text { over } 12 \\
\text { months } \\
\text { between } \\
\text { groups }\end{array}$ \\
\hline $\begin{array}{l}\text { PEPPI-5 } \\
\text { (SD) }\end{array}$ & $\begin{array}{l}38.57 \\
(8.18)\end{array}$ & $\begin{array}{l}39.72 \\
(7.96)\end{array}$ & $\begin{array}{c}0.45 \\
(5.81)\end{array}$ & $\begin{array}{l}39.73 \\
(7.34)\end{array}$ & $\begin{array}{l}38.32 \\
(8.32)\end{array}$ & $\begin{array}{l}-1.04 \\
(6.21)\end{array}$ & 0.042 \\
\hline RAID (0-10) & $\begin{array}{l}3.3 \\
(2.2)\end{array}$ & $3.3(2.1)$ & $0.2(1.8)$ & $\begin{array}{c}3.3 \\
(2.3)\end{array}$ & $3.5(2.3)$ & $0.2(1.8)$ & 0.94 \\
\hline $\begin{array}{l}\text { RAID } \\
\text { (Coping } \\
\text { domain) (0- } \\
\text { 10) }\end{array}$ & $\begin{array}{c}2.6 \\
(2.2)\end{array}$ & $2.8(2.2)$ & $0.2(2.0)$ & $\begin{array}{l}2.7 \\
(2.5)\end{array}$ & $2.8(2.2)$ & $0.0(2.3)$ & 0.87 \\
\hline $\begin{array}{l}\text { Perception } \\
\text { of care } \\
\text { (NRS) (0- } \\
10)\end{array}$ & $\begin{array}{c}8.2 \\
(1.7)\end{array}$ & $8.3(1.6)$ & $0.1(1.4)$ & $\begin{array}{c}8.2 \\
(1.6)\end{array}$ & $7.8(1.8)$ & $-0.4(1.6)$ & 0.01 \\
\hline
\end{tabular}

Results are mean (SD). Bold type represents statistically significant results. 
Figure 2. Number of connections to the Sanoia website over time

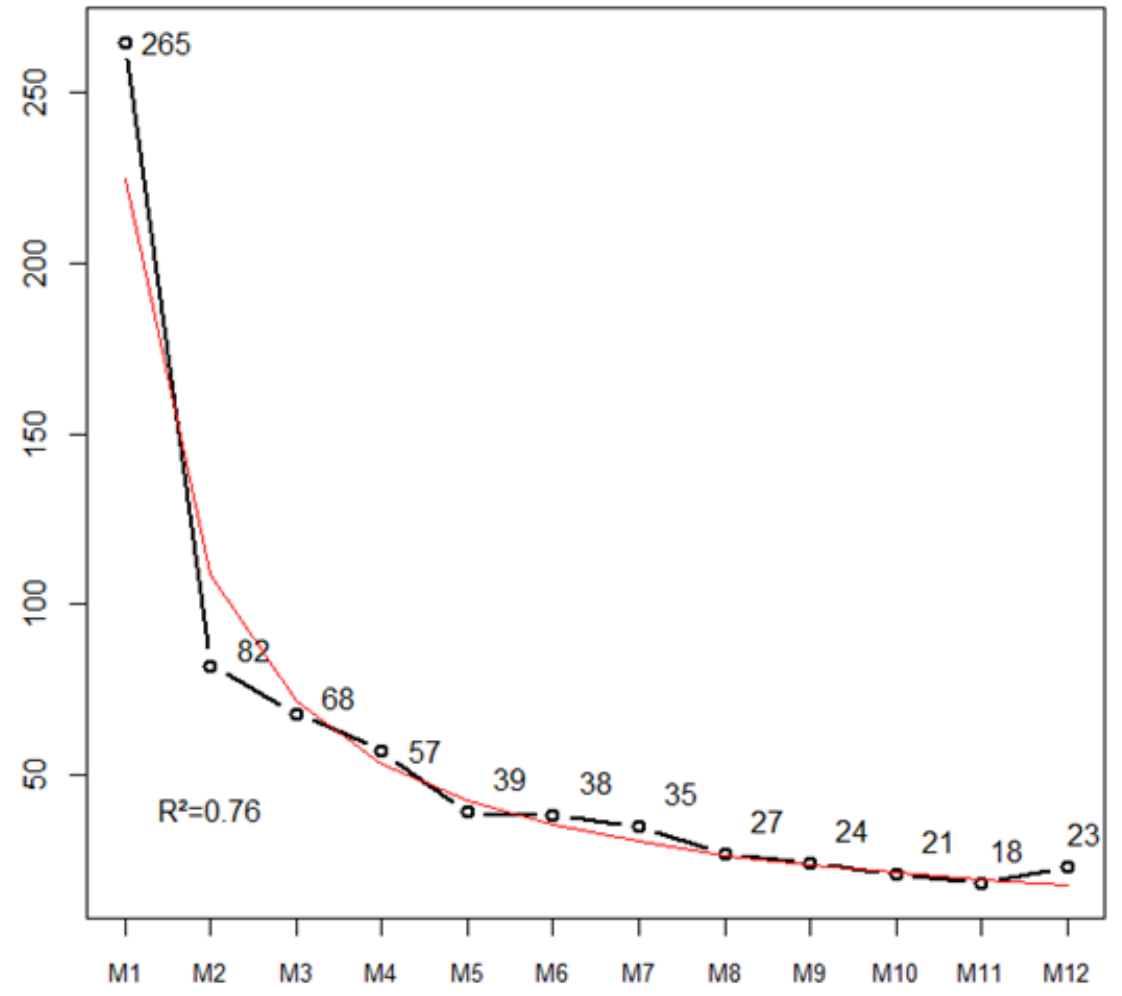

Footnote

The $x$-axis represents months of follow-up and the $y$-axis represents the total number of connections to the website. 


\section{Online supplementary Table 1. The French version of the PEPPI-5 questionnaire}

\section{EFFICACITE PERCUE DE LA RELATION MEDECIN-PATIENT : PEPPI (« perceived efficacy in physician-patient interactions ")}

Les 5 questions suivantes portent sur vos échanges en tant que patient(e), avec les médecins.

Merci d'entourer le chiffre qui indique la confiance que vous ressentez dans votre capacité à faire chacune des choses suivantes. Ces questions portent sur votre capacité à faire ces choses en général et ne concernent pas un médecin en particulier.

Évaluez votre confiance sur une échelle de 0 à 10 , où 10 correspond à 'j'ai totalement confiance en moi' et 0 correspond à 'aucune confiance en moi'.

Quelle confiance avez-vous dans votre capacité :

\section{A savoir quelles questions poser au médecin :}

[0 = aucune confiance en moi, $10=$ totalement confiance en moi]

\begin{tabular}{lllllllllll}
0 & 1 & 2 & 3 & 4 & 5 & 6 & 7 & 8 & 9 & 10 \\
\hline
\end{tabular}

2. A obtenir une réponse à toutes vos questions de la part du médecin :

[0 = aucune confiance en moi, $10=$ totalement confiance en moi]

\begin{tabular}{lllllllllll}
0 & 1 & 2 & 3 & 4 & 5 & 6 & 7 & 8 & 9 & 10 \\
\hline
\end{tabular}

3. A tirer le meilleur des consultations avec vos médecins :

[0 = aucune confiance en moi, $10=$ totalement confiance en moi]

\begin{tabular}{lllllllllll}
0 & 1 & 2 & 3 & 4 & 5 & 6 & 7 & 8 & 9 & 10 \\
\hline
\end{tabular}

4. A obtenir que le médecin prenne au sérieux votre principal souci lié à votre santé :

[0 = aucune confiance en moi, $10=$ totalement confiance en moi $]$

\begin{tabular}{lllllllllll}
0 & 1 & 2 & 3 & 4 & 5 & 6 & 7 & 8 & 9 & 10 \\
\hline
\end{tabular}

5. A obtenir que le médecin fasse quelque chose à propos de votre principal souci lié à votre santé :

[ 0 = aucune confiance en moi, $10=$ totalement confiance en moi]

\begin{tabular}{lllllllllll}
0 & 1 & 2 & 3 & 4 & 5 & 6 & 7 & 8 & 9 & 10 \\
\hline
\end{tabular}


Online supplementary Table 2 Changes in the 5 PEPPI- 5 questions over 12 months

\begin{tabular}{|l|l|l|}
\hline $\begin{array}{l}\text { Number of the PEPPI } \\
\text { question }\end{array}$ & $\begin{array}{l}\text { Change in PEPPI question: } \\
\text { Sanoia group }\end{array}$ & $\begin{array}{l}\text { Change in PEPPI question: } \\
\text { Control group }\end{array}$ \\
\hline 1 & $0.25(1.49)$ & $0.12(1.56)$ \\
\hline 2 & $0.01(1.47)$ & $-0.12(1.68)$ \\
\hline 3 & $0.15(1.39)$ & $-0.19(1.49)$ \\
\hline 4 & $0.14(1.40)$ & $-0.30(1.69)$ \\
\hline 5 & $0.04(1.35)$ & $-0.41(1.37)$ \\
\hline
\end{tabular}

Results are mean (SD) change over 12 months. Positive changes correspond to improvement and negative changes to worsening in the PEPPI. 
Online supplementary Table 3 Causes for dissatisfaction with the platform, presented among the 110 completer patients randomized to the Sanoia group, and presented for patients connecting at least twice or not to the platform (median number of connections=2)

\begin{tabular}{|l|l|l|l|l|}
\hline & $\begin{array}{l}\text { Total } \\
\mathrm{N}=110\end{array}$ & $\begin{array}{l}<2 \\
\text { connections } \\
\mathrm{N}=46\end{array}$ & $\begin{array}{l}\text { >= } \\
\text { connections } \\
\mathrm{N}=64\end{array}$ & P-value \\
\hline Mean (SD) satisfaction & $1.46(1.52)$ & $1.43(1.78)$ & $1.48(1.32)$ & 0.39 \\
\hline $\begin{array}{l}\text { No motive for } \\
\text { dissatisfaction }\end{array}$ & $68 \%$ & $71 \%$ & $66 \%$ & 0.63 \\
\hline $\begin{array}{l}\text { Website } \\
\text { organised }\end{array}$ & $4 \%$ & $2 \%$ & $5 \%$ & 0.85 \\
\hline Technical issues & $3 \%$ & $0 \%$ & $5 \%$ & 0.37 \\
\hline $\begin{array}{l}\text { Fear of internet } \\
\text { Not useful because of }\end{array}$ & $12 \%$ & $13 \%$ & $11 \%$ & 0.97 \\
\hline
\end{tabular}

Percentages are $\%$ of patients 
Online supplementary Figure 1. Screenshots of some of the features of Sanoia: what patients can self-assess and follow in the platform (a: the RAID Questionnaire ; B: graphical follow-up of this score over time).

\section{Sanoïa | Score RAID}

৬ Déconnexion

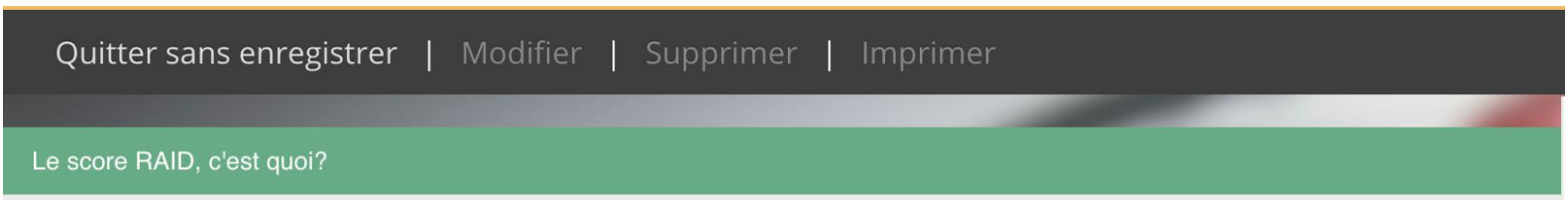

Le score RAID est un score composite de 7 dimensions mesurant l'impact de la Polyarthrite Rhumatoïde sur votre santé au cours des 7 derniers jours.

Date de relevé de votre évaluation

$07 / 10 / 2017$

Faites glisser le curseur au niveau correspondant à lintensité de la douleur que vous avez ressentie au cours des 7 derniers jours à cause de votre polyarthrite rhumatoïde

Aucune douleur

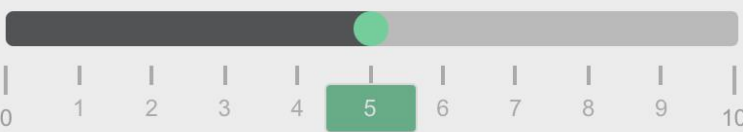

La pire douleur

En considérant toutes les façons dont votre santé a été affectée par la polyarthrite rhumatoïde, faites glisser le curseur au niveau correspondant aux difficultés éprouvées à faire vos activités quotidiennes au cours des 7 derniers jours

Aucune difficulté
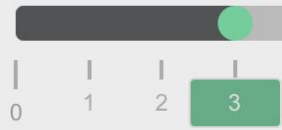

Difficulté extrême

Faites glisser le curseur au niveau correspondant au niveau de fatigue que vous avez ressentie au cours des 7 derniers jours à cause de votre polyarthrite rhumatoïde

Aucune fatigue

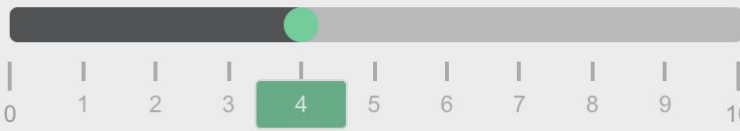

La pire fatigue 


\section{Sanoïa | Score RAID}

* Personnaliser U Déconnexion

\section{« Retour | Imprimer}

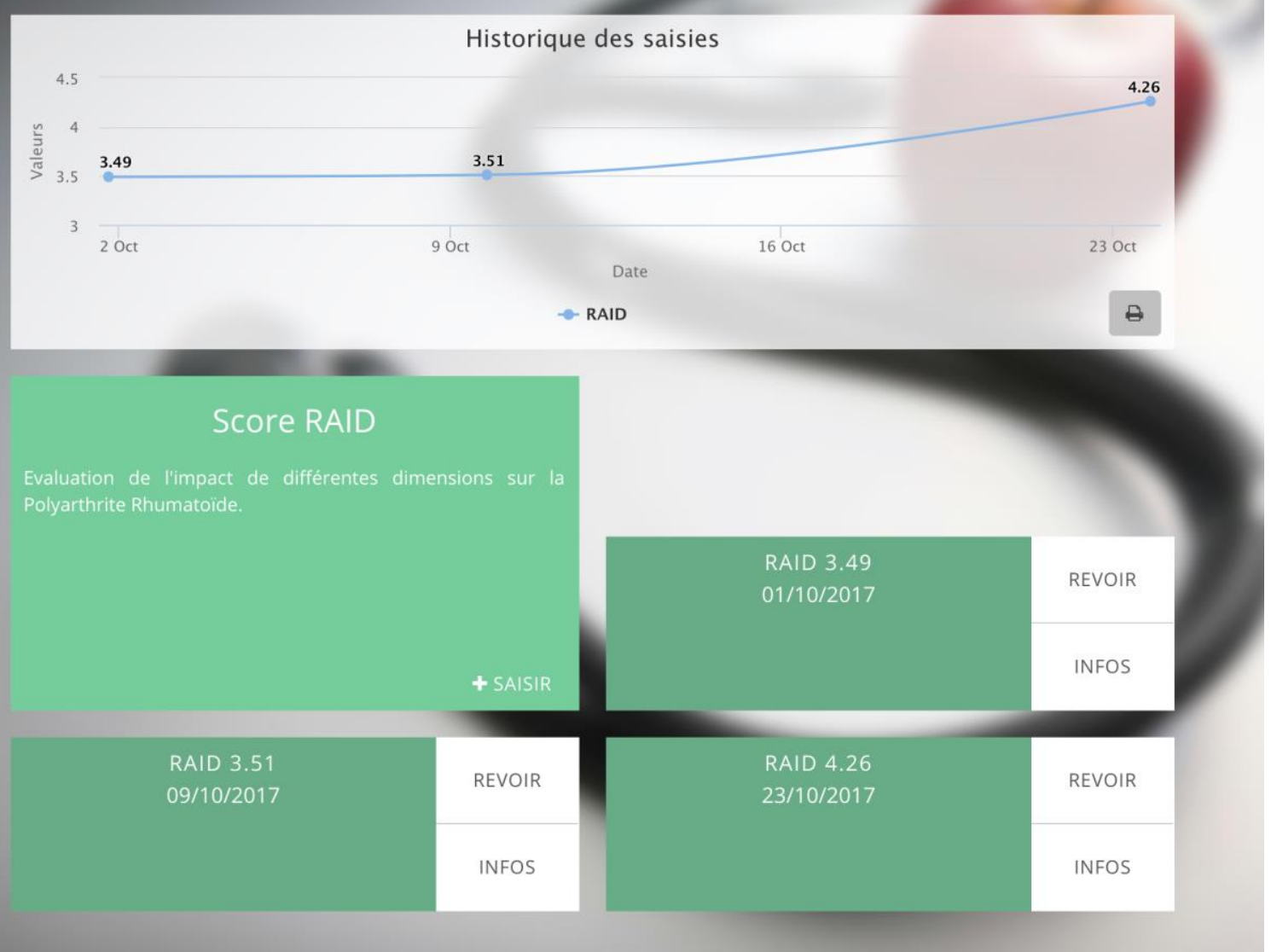

